\title{
Effects of Temperature and Moisture on Sheet Molding Compounds
}

\author{
GEORGE S. SPRINGER \\ Department of Mechanical Engineering \\ and Applied Mechanics \\ The University of Michigan \\ Ann Arbor, Michigan 48109
}

(Received August 20, 1982)

\section{SUMMARY}

A summary is given on the effects of moisture and temperature on the properties of chopped fiber reinforced sheet molding compounds. The properties surveyed include tensile strength and modulus, compression strength and modulus, shear strength and modulus, flexural strength and modulus, fatigue, creep, vibration damping, moisture absorption characteristics, and thermal expansion.

\section{INTRODUCTION}

\begin{abstract}
$\mathbf{0}$ WING TO THEIR FAVORABLE PERFORMANCE CHARACTERISTICS, LIGHT weight composite materials have been gaining wide applications in commercial, space, and military applications. For this reason, in recent years several investigators have measured the properties of glass fiber reinforced sheet molding compounds (SMC). In this report a summary is given of the effects of temperature and moisture on the engineering properties of SMC materials. In presenting the results emphasis is placed on the main features and characteristics of the data. Readers interested in details of the material behavior are referred to the appropriate references quoted in the text, figure captions, and table headings. A brief summary of static properties at room temperature is given in Table 1. Further information regarding room temperature properties may be found in reference 1 .

Sheet molding compounds consist of polyester (or, less frequently, vinylester or epoxy) resins reinforced with glass fibers. The fibers may be randomly oriented (designated as SMC-R) or may be continuous (SMC-C and XMC). A material may also contain a combination of chopped and continuous fibers (SMC-C/R and XMC-3). Numbers added after the letters $R$ and $C$ indicate the weight percent of chopped and continuous fibers, respectively. XMC contains $75 \%$ glass fibers by weight. Typical formulations and densities of different types of materials are given in Tables 2 and 3.
\end{abstract}


Table 1. Room temperature tensile strength and modulus $\left(S_{t}\right.$ and $E_{t}$,

Poisson's ratio (v), compressive strength and modulus $\left(S_{c}\right.$ and $E_{c}$. flexural strength and modulus $\left(S_{f}\right.$ and $\left.E_{f}\right)$, in plane shear strength and modulus $\left(S_{L T}\right.$ and $E_{L T}$, and short beam shear strength and modulus $\left(S_{S}\right.$ and $G_{S}$ ). L-longidutinal, T-transverse direction. Strength in MPa and modulus in GPa (refs. 2-7).

\begin{tabular}{lrcccccccccc}
\hline Material & $\mathbf{S}_{\mathbf{t}}$ & $\mathbf{E}_{\mathbf{t}}$ & $v$ & $\mathbf{S}_{\mathbf{c}}$ & $\mathbf{E}_{\mathbf{c}}$ & $\mathbf{S}_{\boldsymbol{f}}$ & $\mathbf{E}_{\mathbf{f}}$ & $\mathbf{S}_{\mathbf{L T}}$ & $\mathbf{E}_{\mathbf{L T}}$ & $\mathbf{S}_{\mathbf{S}}$ & $\mathbf{G}_{\mathbf{S}}$ \\
\hline XMC-3(L) & 561 & 35.7 & 0.31 & 480 & 37 & $\mathbf{9 7 3}$ & 34.1 & $\mathbf{9 1 . 2}$ & 4.47 & 55 & - \\
XMC-3(T) & 70 & 12.3 & 0.116 & 160 & 14.5 & 139 & 6.8 & & & & \\
SMC-C20/R30(L) & 289 & 21.4 & 0.3 & 306 & 20.4 & 645 & 25.7 & 85.4 & 4.09 & 41 & - \\
SMC-C20/R30(T) & 84 & 12.4 & 0.18 & 166 & 12.2 & 165 & 5.9 & & & & \\
SMC-R25 & 82 & 13.3 & 0.25 & 183 & 11.7 & 220 & 4.8 & 79 & 4.48 & 30 & 5 \\
SMC-R50 & 164 & 15.8 & 0.31 & 225 & 15.9 & 314 & 14.0 & 62 & 5.94 & 25 & 7 \\
SMC-R57 & 160 & 16.5 & - & - & - & - & - & - & - & - & - \\
SMC-R65 & 227 & 14.7 & 0.26 & 241 & 17.9 & 403 & 5.7 & 128 & 5.38 & 45 & - \\
EA SMC-R30 & 30 & 8.7 & 0.30 & - & - & - & - & - & - & - & - \\
VE-SMC-R50 & 165 & 7.0 & - & - & - & - & - & - & - & 50 & 4 \\
VE-SMC-C40/R10(L) & 426 & - & - & - & - & - & - & - & - & - & - \\
VE-SMC-C40/R10(T) & 57 & - & - & - & - & - & - & - & - & - & - \\
VE-XMC-3(L) & 648 & - & - & - & - & - & - & - & - & - & - \\
VE-XMC-3(T) & 74 & - & - & - & - & - & - & - & - & - & - \\
\hline
\end{tabular}

Table 2. Material formulations and densities of SMC materials. (PPG-PPG Industries, OFC-Owens Corning Fiberglas) (refs. 2,3).

\begin{tabular}{|c|c|c|c|c|}
\hline \multirow[b]{2}{*}{ Material } & \multirow[b]{2}{*}{ Ingredient } & \multirow[b]{2}{*}{ Type } & \multicolumn{2}{|c|}{ Weight Density } \\
\hline & & & $\%$ & $\mathrm{~kg} / \mathrm{m}^{3}$ \\
\hline \multirow[t]{7}{*}{$\mathrm{XMC}-3$} & $\begin{array}{l}\text { Continuous Glass Fibers- } \\
\pm 7.5^{\circ}, \text { X-Pattern }\end{array}$ & $\begin{array}{l}\text { PPG XMC Strand } \\
\text { Type } 1064\end{array}$ & 50 & \\
\hline & $\begin{array}{l}2.54 \mathrm{~cm} \text { Chopped Glass } \\
\text { Fibers }\end{array}$ & $\begin{array}{l}\text { PPG XMC Strand } \\
\text { Type } 1064\end{array}$ & 25 & \\
\hline & Resin & $\begin{array}{l}\text { PPG Selectron RS-50335 } \\
\text { Isophthalic Polyester }\end{array}$ & 21.5 & 1970 \\
\hline & Monomer & Styrene & 2.4 & \\
\hline & Thickener & PPG Selectron RS-5988 & 0.8 & \\
\hline & Catalyst & TBPB & 0.2 & \\
\hline & Mold Release & Zinc Stearate & 0.1 & \\
\hline \multirow[t]{8}{*}{ SMC-C20/R30 } & $\begin{array}{l}\text { Continuous Glass } \\
\text { Fibers - Aligned }\end{array}$ & OCF 433AB Roving & 20 & \\
\hline & $\begin{array}{l}2.54 \mathrm{~cm} \text { Chopped Glass } \\
\text { Fibers }\end{array}$ & OCF 433AB Roving & 30 & \\
\hline & Resin & OCF-E980 Polyester & 32.3 & \\
\hline & Filler & Calcium Carbonate & 16.1 & 1810 \\
\hline & Mold Release & Zinc Stearate & 0.8 & \\
\hline & Thickener & Magnesium Oxide & 0.5 & \\
\hline & Catalyst & TBP & 0.3 & \\
\hline & Inhibitor & Benzoquinone & Trace & \\
\hline
\end{tabular}


Table 2. (Continued)

\begin{tabular}{|c|c|c|c|c|}
\hline \multirow[b]{2}{*}{ Material } & \multirow[b]{2}{*}{ Ingredient } & \multirow[b]{2}{*}{ Type } & \multicolumn{2}{|c|}{ Weight Density } \\
\hline & & & $\%$ & $\mathrm{~kg} / \mathrm{m}^{3}$ \\
\hline \multirow[t]{8}{*}{ SMC-R25 } & $2.54 \mathrm{~cm}$ Chopped Glass Fibers & E-Glass (OCF $951 \mathrm{AB}$ ) & 25 & \\
\hline & Resin & Polyester (OCF E-920-1) & 29.4 & \\
\hline & Filler & Calcium Carbonate & 41.8 & \\
\hline & Internal Release & Zinc Stearate & 1.1 & \\
\hline & Catalyst & Tertiary Butyl & & \\
\hline & & Perbenzoate & 0.3 & 1830 \\
\hline & Thickener & Magnesium Hydroxide & 1.5 & \\
\hline & Pigment & Mapico Black & 0.8 & \\
\hline \multirow[t]{7}{*}{ SMC-R50 } & $\begin{array}{l}2.54 \mathrm{~cm} \text { Chopped Glass } \\
\text { Fibers }\end{array}$ & OCF $433 \mathrm{AB}$ & 50 & \\
\hline & Resin & OCF-E980 Polyester & 32.3 & \\
\hline & Filler & Calcium Carbonate & 16.1 & \\
\hline & Mold Release & Zinc Stearate & 0.8 & 1870 \\
\hline & Thickener & Magnesium Oxide & 0.5 & \\
\hline & Catalyst & TBP & 0.3 & \\
\hline & Inhibitor & Benzoquinone & Trace & \\
\hline \multirow[t]{2}{*}{ SMC-R57 } & Formulated Epoxy Resin & $\begin{array}{l}\text { Epoxy Sheet Molding } \\
\text { Compound (Gulf 1057) }\end{array}$ & 43 & \\
\hline & $1.27 \mathrm{~cm}$ Chopped Glass Fibers & E-Glass (OCF-495) & 57 & 1740 \\
\hline \multirow[t]{4}{*}{ SMC-R65 } & $2.54 \mathrm{~cm}$ Chopped Glass Fibers & E-Glass (PPG 518) & 65 & \\
\hline & Rigid Resin & Polyester (PPG 50271) & 16 & \\
\hline & Flexible Resin & Polyester (PPG 50161) & 16 & 1820 \\
\hline & Thickener, etc. & & & \\
\hline \multirow[t]{4}{*}{ EA-SMC-R30 } & $2.54 \mathrm{~cm}$ Chopped Glass Fibers & E-Glass (OCF 956) & 28 & \\
\hline & Resin & Polyester & 19.9 & \\
\hline & Filler & Calcium Carbonate & 41 & 1830 \\
\hline & Thickener & Balance & 11.1 & \\
\hline
\end{tabular}

\section{STATIC PROPERTIES}

Tensile Strength and Modulus. The environment has a marked effect on the tensile strength and modulus. Generally, both the ultimate tensile strength and the tensile modulus decrease at elevated temperatures (Figure 1) and during exposure to different types of fluids (Tables 4-5). The decrease in properties depends on the temperature, the type of fluid, and the length of exposure. Interestingly, under some conditions there is a slight $(\sim 10 \%)$ increase in both the tensile strength and the tensile modulus. The increase is probably due to plasticization of the material.

Compressive Strength and Modulus. Both the compressive strength and modulus depend on the material composition, on the fiber orientation, and on the temperature, as shown in Figure 2. As expected, the strength and the 
Table 3. VE-SMC-R50 paste formulation.

\begin{tabular}{lr}
\hline Component & Parts \\
\hline A-SIDE & \\
XD-9013.03 & 10 \\
TBPB & 1 \\
Camelwite & 92 \\
Zinc Stearate & 3 \\
B-SIDE & \\
Derakane* 470-45 & 100 \\
Maglite D & 50 \\
Camelwite & 100 \\
Pump 10-14/1 by weight A/B & \\
Max viscosity = $6000 \mathrm{cps}$ & \\
(9OF, RVT, \# 4 Spindle, 20 rpm) &
\end{tabular}

*Registered Trademark of Dow Chemical Company.

modulus are highest along the fiber direction of composites containing continuous fibers (XMC-3 and SMC-C20/R30).

Shear Strength and Modulus. In most cases there is a significant decrease in the shear strength and in the shear modulus at elevated temperature (Table 6) and during exposure to humid air and to different types of liquids
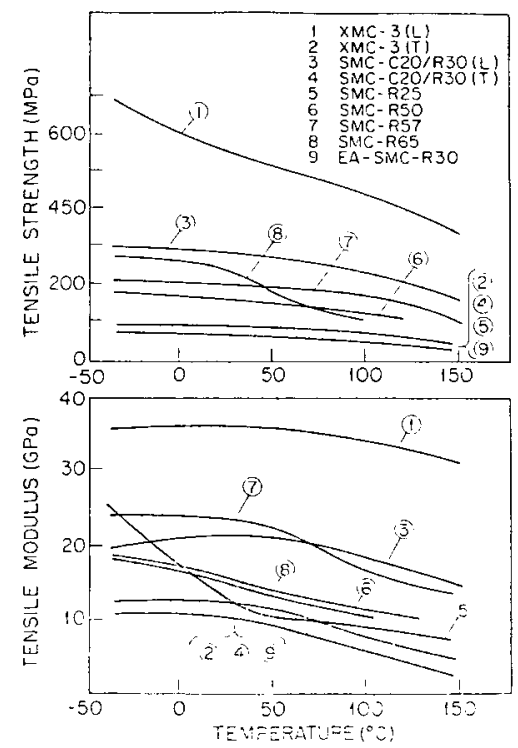

Figure 1. The effect of the amount of chopped fibers on the tensile strength of XMC-3 composites. Total fiber content by weight $=75$ percent (ref. 8). 
Table 4. Tensile strength reteined (percent) after immersion in different fluids for 30 and 180 days. (L-longitudinal, T-transverse direction) (refs. 3,4).

\begin{tabular}{|c|c|c|c|c|c|c|c|c|}
\hline \multirow[b]{2}{*}{ Fluid } & \multicolumn{4}{|c|}{$\begin{array}{l}\text { SMC- } \\
\text { C2O/ }\end{array}$} & \multicolumn{2}{|c|}{ SMC-R50 } & \multicolumn{2}{|c|}{ VE-SMC-R50 } \\
\hline & \multicolumn{8}{|c|}{30 days 30 days 30 days 180 days 30 days 180 days 30 days 180 days } \\
\hline Water, 23C & $\begin{array}{r}89(\mathrm{~L}) \\
107(\mathrm{~T})\end{array}$ & $\begin{array}{r}103(\mathrm{~L}) \\
73(\mathrm{~T})\end{array}$ & - & - & - & - & - & - \\
\hline $\begin{array}{l}\text { Humid Air, } 23 \mathrm{C} \text {, } \\
50 \% \text { r.h }\end{array}$ & - & - & 100 & 90 & 100 & 100 & 100 & 105 \\
\hline $\begin{array}{l}\text { Humid Air, 93C, } \\
50 \% \text { r.h }\end{array}$ & - & - & 95 & 95 & 100 & 90 & 105 & 102 \\
\hline $\begin{array}{l}\text { Humid Air, } 23 \mathrm{C} \text {, } \\
100 \% \text { r.h }\end{array}$ & - & - & 90 & 80 & 95 & 80 & 105 & 75 \\
\hline $\begin{array}{l}\text { Humid Air, } 93 \mathrm{C} \text {, } \\
100 \% \text {, r.h }\end{array}$ & - & - & 95 & 55 & 95 & 65 & 95 & 55 \\
\hline Salt Water 23C & $\begin{array}{r}95(\mathrm{~L}) \\
107(\mathrm{~T})\end{array}$ & $\begin{array}{l}90(L) \\
87(T)\end{array}$ & 95 & 65 & 105 & 80 & 102 & 80 \\
\hline Salt Water, 93C & - & - & 70 & 45 & 105 & 50 & 85 & 53 \\
\hline No. 2 Diesel, $23 \mathrm{C}$ & - & - & 90 & 90 & 98 & 98 & 103 & 105 \\
\hline No. 2 Diesel, 93C & - & - & 95 & 90 & 98 & 98 & 101 & 102 \\
\hline Motor Oil, 23C & $\begin{array}{r}95(L) \\
110(T)\end{array}$ & $\begin{array}{l}100(\mathrm{~L}) \\
108(\mathrm{~T})\end{array}$ & 95 & 80 & 95 & 95 & 95 & 102 \\
\hline Motor Oil 93C & - & - & 90 & 80 & 90 & 97 & 105 & 102 \\
\hline Antifreeze, $23 \mathrm{C}$ & $\begin{array}{r}95(\mathrm{~L}) \\
110(\mathrm{~T})\end{array}$ & $\begin{array}{r}78(\mathrm{~L}) \\
108(\mathrm{~T})\end{array}$ & 95 & 80 & 95 & 95 & 95 & 105 \\
\hline Antifreeze, $93 \mathrm{C}$ & - & - & 75 & 30 & 85 & 30 & 105 & 45 \\
\hline Gasoline, $23 \mathrm{C}$ & $\begin{array}{r}97(\mathrm{~L}) \\
108(\mathrm{~T})\end{array}$ & $\begin{array}{r}101(\mathrm{~L}) \\
96(\mathrm{~T})\end{array}$ & 90 & 90 & 100 & 100 & 100 & 95 \\
\hline Gasoline, 93C & - & - & 75 & 70 & 95 & 70 & 105 & 85 \\
\hline $\begin{array}{l}\text { Transmission } \\
\text { Fluid, 23C }\end{array}$ & $\begin{array}{r}99(\mathrm{~L}) \\
120(\mathrm{~T})\end{array}$ & $\begin{array}{r}82(L) \\
110(T)\end{array}$ & - & - & - & - & - & - \\
\hline Break Fluid, $23 \mathrm{C}$ & $\begin{array}{l}97(\mathrm{~L}) \\
93(\mathrm{~T})\end{array}$ & $\begin{array}{r}97(L) \\
109(T)\end{array}$ & - & - & - & - & - & - \\
\hline
\end{tabular}

(Tables 7,8$)$. As in the case of tensile properties, shear properties also increase slightly under some conditions. Again, this increase is caused by plasticization on the material.

Flexural Strength and Modulus. The flexural strength and modulus decrease with increasing temperature, as illustrated in Figure 3.

\section{FATIGUE}

The effect of temperature on tension-tension fatigue life is illustrated in Figures 4 and 5. For chopped fiber composites (SMC-R25 and SMC-R65) 
Table 5. Tensile modulus retained (percent) after immersion in different fluids for 30 and 180 days (ref. 4 ).

\begin{tabular}{|c|c|c|c|c|c|c|}
\hline \multirow[b]{2}{*}{ Fluid } & \multicolumn{2}{|c|}{ SMC-R25 } & \multicolumn{2}{|c|}{ SMC-R50 } & \multicolumn{2}{|c|}{ VE-SMC-R50 } \\
\hline & 30 days & 180 days & 30 days & 180 days & 30 days & 180 days \\
\hline Humid Air, 23C, $50 \%$ r.h & 105 & 110 & 100 & 90 & 98 & 95 \\
\hline Humid Air, 93C, $50 \%$ r.h & 120 & 110 & 90 & 80 & 95 & $\mathbf{9 0}$ \\
\hline Humid Air, 23C, $100 \%$ r.h & 100 & 95 & 90 & 80 & 95 & 90 \\
\hline Humid Air, 93C, $100 \%$ r.h & 120 & 110 & 85 & 80 & 90 & 90 \\
\hline Salt Water, $23 C$ & 90 & 95 & 90 & 80 & 95 & 90 \\
\hline Salt Water, $93 C$ & 110 & 90 & 85 & 65 & 90 & 85 \\
\hline No. 2 Diesel, $23 \mathrm{C}$ & 110 & 115 & 90 & 90 & 95 & 95 \\
\hline No. 2 Diesel, 93C & 120 & 95 & 95 & 90 & 90 & 90 \\
\hline Motor Oil, 23C & 95 & 110 & 80 & 90 & 90 & 95 \\
\hline Motor Oil, 93C & 110 & 115 & 90 & 90 & 95 & 95 \\
\hline Antifreeze, $23 \mathrm{C}$ & 90 & 110 & 85 & 80 & 90 & 95 \\
\hline Antifreeze, $93 \mathrm{C}$ & 85 & 85 & 80 & 50 & 90 & 75 \\
\hline Gasoline, 23C & 95 & 90 & 85 & 85 & 95 & 90 \\
\hline Gasoline, 93C & 80 & 80 & 88 & 60 & 85 & 75 \\
\hline
\end{tabular}

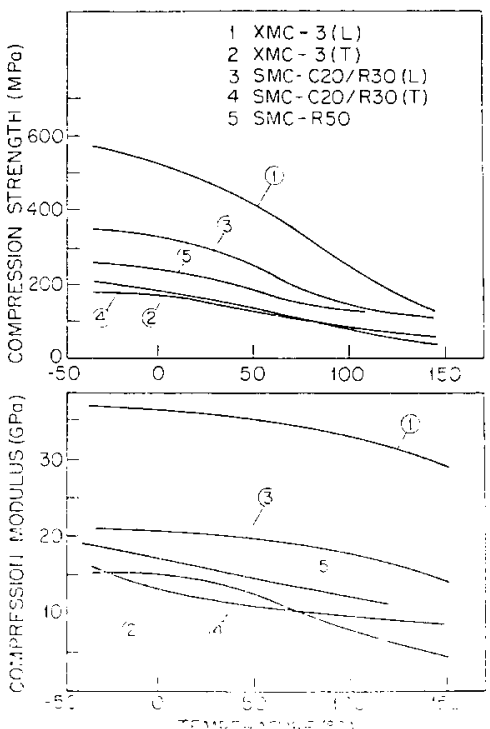

Figure 2. The effect of temperature on the compression strength and compression modulus. (L-longitudinal, T-transverse direction) (ref. 3). 
Table 6. Losses in in-plane shear strength $\left(S_{L}\right.$ ), shear modulus $\left(E_{L T}\right)$, and ultimate shear strain $\left(\varepsilon_{L}\right)$ when the temperature is raised from $23 \mathrm{C}$ to $93 \mathrm{C}$ (ref. 3).

\begin{tabular}{lccr}
\hline & & LOSS (Percent) \\
\cline { 2 - 4 } & $S_{\mathrm{LT}}$ & $E_{\mathrm{LT}}$ & $\varepsilon_{\mathrm{LT}}$ \\
\hline XMC-3 & 38 & 48 & 13 \\
SMC-C20/R30 & 40 & 44 & 0.7 \\
SMC-R50 & - & 22 & - \\
\hline
\end{tabular}

an increase in temperature from $23 \mathrm{C}$ to $93 \mathrm{C}$ results in about a two-fold decrease in fatigue strength of the material. The fatigue strengths of materials containing continuous fibers (XMC-3 and SMC-C20/R30) seem to be affected less by changes in temperature than by the orientation of the fibers.

\section{CREEP}

The results of static creep tests are presented in Figures 6-12. The curves are average values. There is considerable scatter in the actual data. An arrow at the end of a curve indicates that the specimen did not fail at the end of the test, while a cross indicates specimen failure.

As expected, the strain increases with load, temperature, relative hu-

Table 7. Short beam shear strength retained (percent) after immersion in different fluids for $\mathbf{3 0}$ and 180 days (ref. 4).

\begin{tabular}{|c|c|c|c|c|c|c|}
\hline \multirow[b]{2}{*}{ Fluid } & \multicolumn{2}{|c|}{ SMC-R25 } & \multicolumn{2}{|c|}{ SMC-R50 } & \multicolumn{2}{|c|}{ VE-SMC-R50 } \\
\hline & 30 days & 180 days & 30 days & 180 days & 30 days & 180 days \\
\hline Humid Air $23 \mathrm{C}, 50 \%$ r.h & 105 & 120 & 110 & 110 & 100 & 103 \\
\hline Humid Air $93 \mathrm{C}, 50 \%$ r.h & 120 & 110 & 98 & 110 & 105 & 120 \\
\hline Humid Air $23 \mathrm{C}, 100 \%$ r.h & 110 & 110 & 90 & 95 & 95 & 95 \\
\hline Humid Air $93 \mathrm{C}, 100 \%$ r.h & 102 & 95 & 92 & 85 & 95 & 95 \\
\hline Salt Water $23 C$ & 110 & 100 & 95 & 95 & 99 & 98 \\
\hline Salt Water 93C & 95 & 65 & 80 & 35 & 95 & 75 \\
\hline No. 2 Diesel 23C & 115 & 120 & 90 & 75 & 95 & 110 \\
\hline No. 2 Diesel 93C & 125 & 125 & 103 & 110 & 100 & 105 \\
\hline Motor Oil 23C & 100 & 125 & 85 & 95 & 90 & 115 \\
\hline Motor Oil 93C & 110 & 120 & 90 & 110 & 95 & 120 \\
\hline Antifreeze $23 \mathrm{C}$ & 105 & 110 & 90 & 100 & 95 & 105 \\
\hline Antifreeze $93 \mathrm{C}$ & 75 & 55 & 50 & 15 & 85 & 50 \\
\hline Gasoline 23C & 95 & 95 & 80 & 95 & 98 & 99 \\
\hline Gasoline 93C & 70 & 75 & 85 & 85 & 75 & 75 \\
\hline
\end{tabular}


Table 8. Short beam shear modulus retained (percent) after immersion in different fluids for $\mathbf{3 0}$ and 180 days (ref. 4).

\begin{tabular}{|c|c|c|c|c|c|c|}
\hline \multirow[b]{2}{*}{ Fluid } & \multicolumn{2}{|c|}{ SMC-R25 } & \multicolumn{2}{|c|}{ SMC-R50 } & \multicolumn{2}{|c|}{ VE-SMC-R50 } \\
\hline & 30 days & 180 days & 30 days & 180 days & 30 days & 180 days \\
\hline Humid Air $23 \mathrm{C}, 50 \%$ r.h & 110 & 125 & 105 & 100 & 105 & 115 \\
\hline Humid Air $93 \mathrm{C}, 50 \%$ r.h & 125 & 115 & 95 & 95 & 110 & 120 \\
\hline Humid Air $23 \mathrm{C}, 100 \%$ r.h & 100 & 115 & 85 & 85 & 90 & 95 \\
\hline Humid Air $93 \mathrm{C}, 100 \% \mathrm{r} . \mathrm{h}$ & 115 & 120 & 95 & 85 & 105 & 105 \\
\hline Salt Water $23 C$ & 110 & 100 & 85 & 90 & 100 & 95 \\
\hline Salt Water 93C & 85 & 80 & 65 & 50 & 90 & 95 \\
\hline No. 2 Diesel $23 \mathrm{C}$ & 125 & 120 & 95 & 95 & 105 & 115 \\
\hline No. 2 Diesel 93C & 110 & 115 & 95 & 95 & 110 & 110 \\
\hline Motor Oil $23 \mathrm{C}$ & 105 & 125 & 75 & 90 & 90 & 110 \\
\hline Motor Oil 93C & 105 & 125 & 85 & 95 & 90 & 115 \\
\hline Antifreeze $23 C$ & 105 & 115 & 75 & 90 & 90 & 110 \\
\hline Antifreeze 93C & 80 & 75 & 54 & 15 & 85 & 55 \\
\hline Gasoline 23C & 95 & 90 & 80 & 95 & 105 & 110 \\
\hline Gasoline $93 \mathrm{C}$ & 60 & 85 & 70 & 70 & 80 & 75 \\
\hline
\end{tabular}
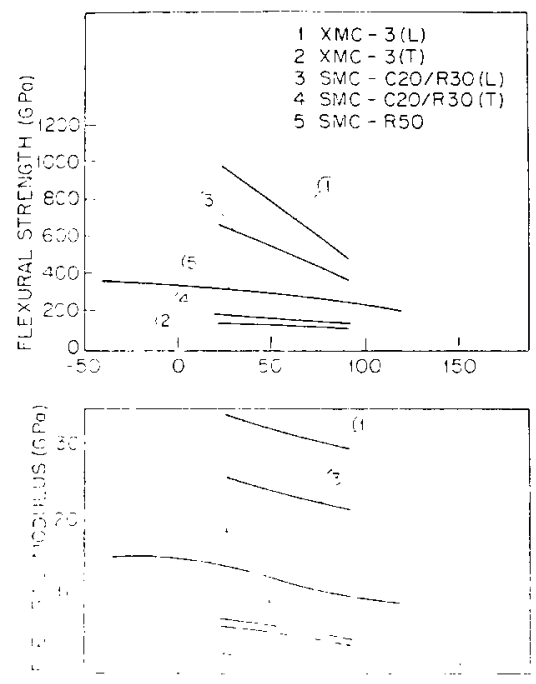

Figure 3. The effect of temperature on the flexural strength and flexural modulus. (L-longitude, T-transverse direction) (ref. 3). 


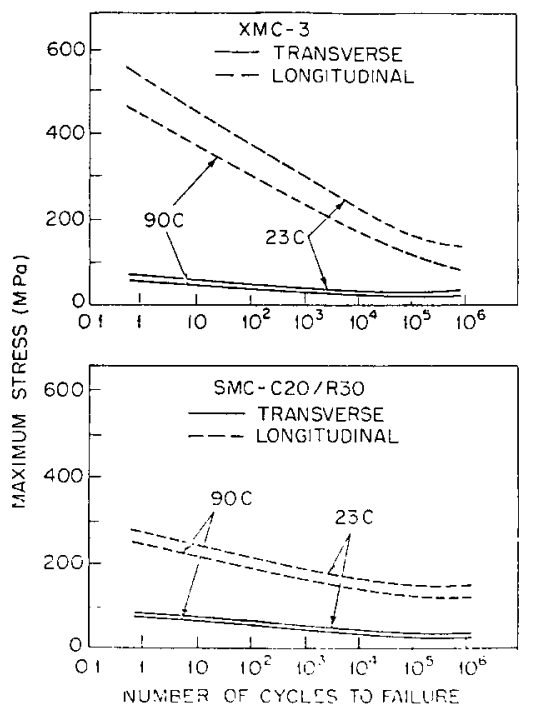

Figure 4. Tension-tension fatigue results. $R=0.05$ (ref. 3 ).

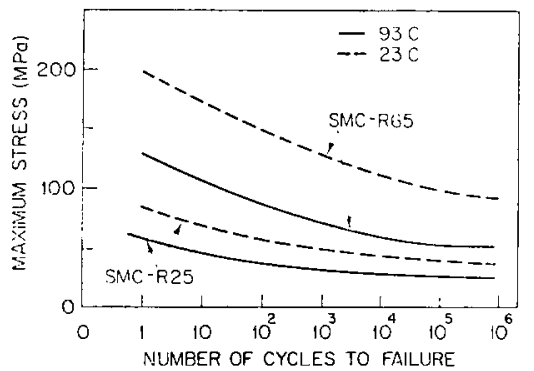

Figure 5. Tension-tension fatigue results. $R=0.05$ (ref. 2).
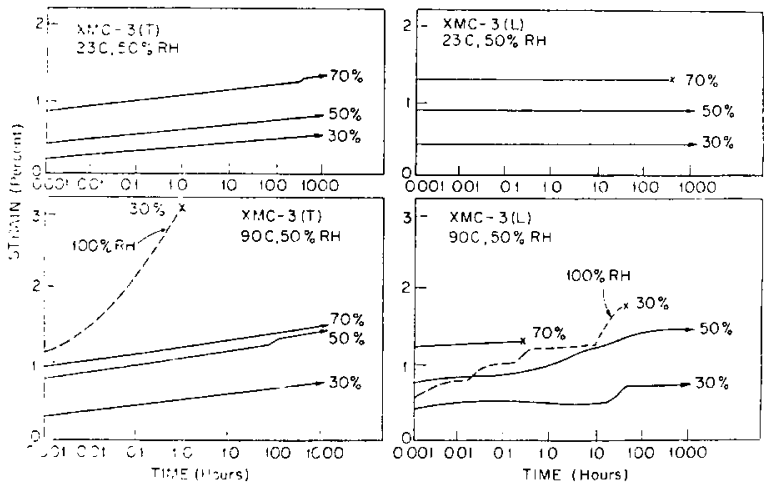

Figure 6. Creep of XMC-3 at 70, 50, and 30 percent of static ultimate tensile strength (L-longitudinal, T-transverse direction) (ref 3). 


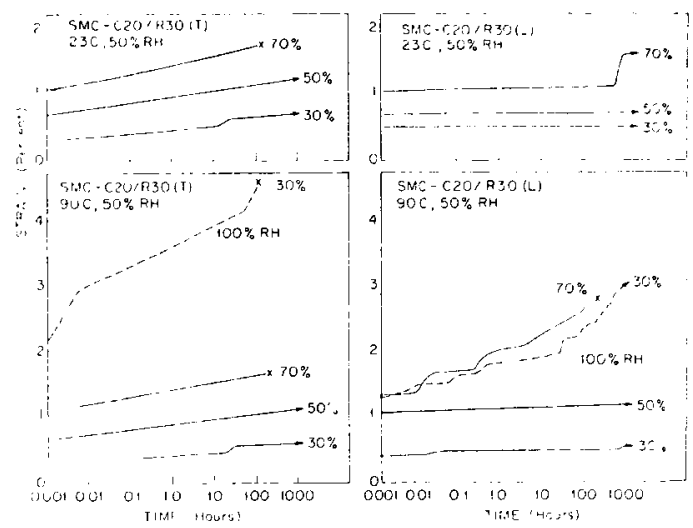

Figure 7. Creep of SMC-C20/R30 at 70,50 and 30 percent of static ultimate tensile strength. (L-longitudinal, T-transverse direction) (ref. 3).

midity, and time. The increase in strain with time is not uniform. Step "jumps" occur in strain at random times. Because of these unpredictable jumps, the strain cannot be described by simple viscoelastic models.

Heimbuch and Sanders [2] investigated the stress rupture of SMC-R25, SMC-R57 and SMC-R65 composites in air at 23,60, 90C and at 50\% and $100 \%$ relative humidities. Owing to the large scatter in the data, the effect of the environment on stress rupture cannot be ascertained from the results of these tests.

\section{ADHESIVE BONDED SINGLE LAP JOINTS}

The results presented in this section were obtained with single lap joints

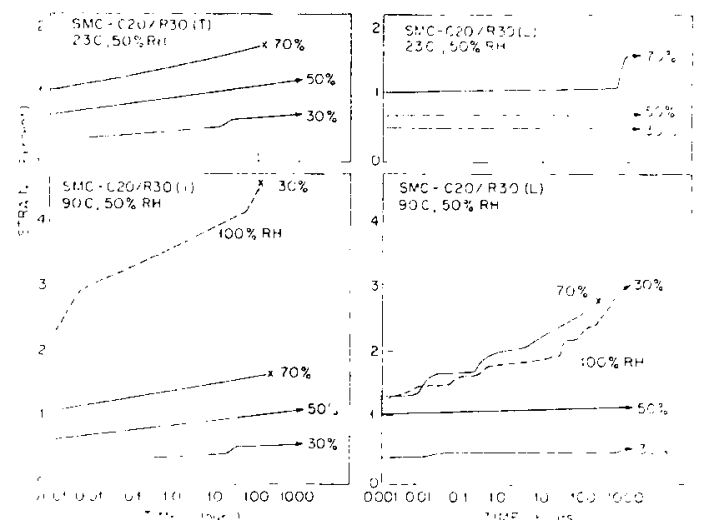

Figure 8. Creep of SMC-C20/R30 at 70, 50 and 30 percent of static ultimate tensile strength. (L-longitudinal, T-transverse direction) (ref. 3). 


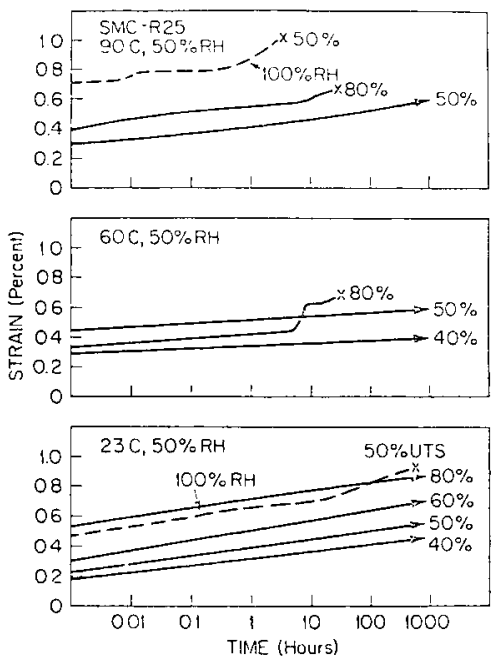

Figure 9. Creep of SMC-R25 under different loads (percent of static ultimate tensile strength) (ref. 2).

bonded with a two part urethane adhesive, characterized in detail in reference [9].

Moisture Absorption Characteristics. Typical moisture absorption data obtained with XMC-3 to SMC-R50 joints are given in Figure 13. Data for SMC-R50 to SMC-R50 joints exhibit similar trends. At $23 \mathrm{C}$ both XMC-3 to SMC-R50 and SMC-R50 to SMC-R50 joints seem to approach asymptotically the same maximum moisture content $(\mathrm{Mm})$ when immersed in the same fluid. During a two month test period Mm is reached only in air. In water and in 5\% NaCl-water mixture the maximum moisture contents are not attained. The Mm values can be estimated by extrapolating the data,

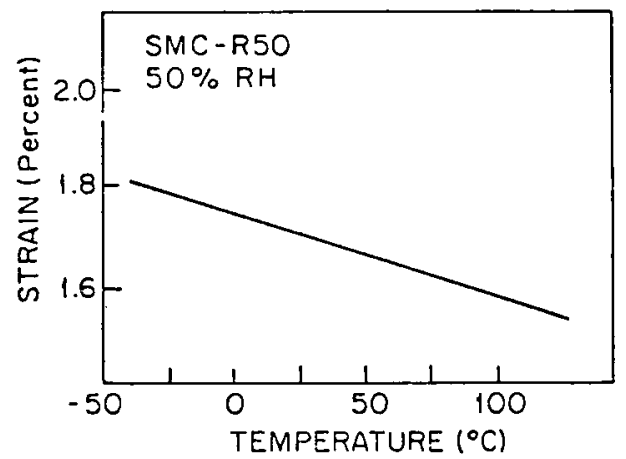

Figure 10. Strain (elongation) of SMC-RSO at failure as a function of temperature (ref. S). 

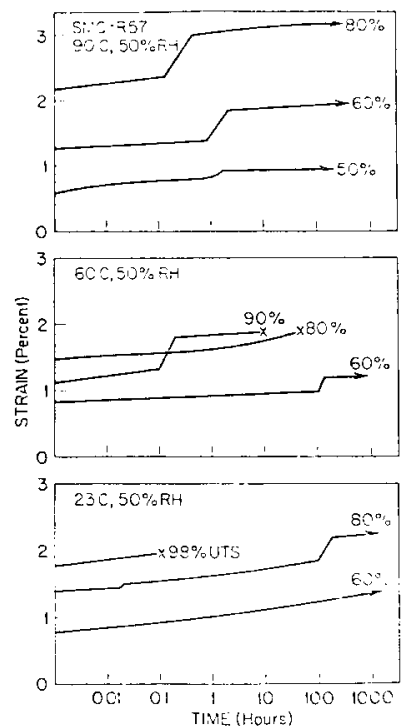

Figure 11. Creep of SMC-R57 under different loads (percent of static ultimate tensile strength) (ref. 2).
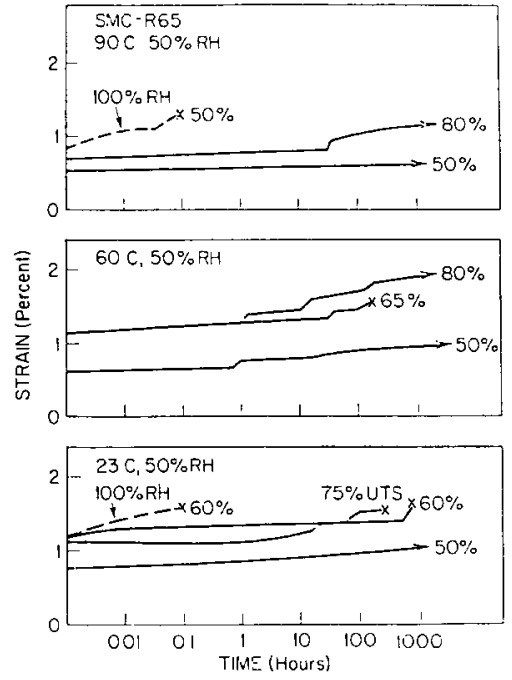

Figure 12. Creep of SMC-R65 under different loads (percent of static ultimate tensile strength (ref. 2). 


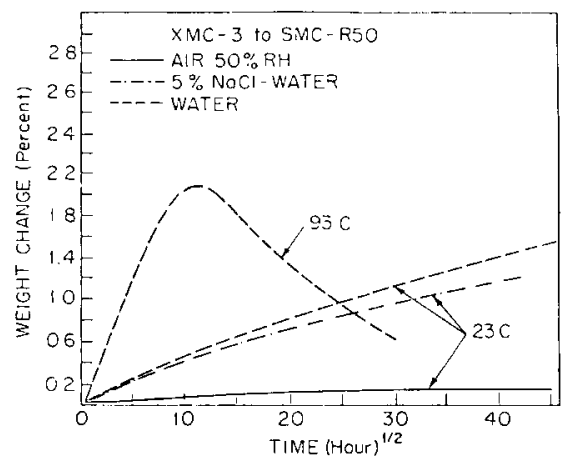

Figure 13. Moisture absorption of adhesive bonded XMC-3 to SMC-R50 single lap joints.

giving $0.18,1.5$ and 2.0 percent for air, salt water, and water, respectively.

At 93C (immersion in water) the maximum moisture level is not approached asymptotically. Here the weight increases for about the first 100 hours and then decreases at a rapid rate. This indicates that the material deteriorates during exposure. At $93 \mathrm{C}$ both bonded and unbonded test specimens behave similarly, suggesting that degradation is mostly in the composite and not in the adhesive.

Joints loaded up to 30 percent of their strength did not show appreciable change in their moisture absorption characteristics.

Lap Shear Strength. Lap shear strengths of adhesive bonded single lap joints are given in Table 9. Changes in baseline strength and modulus during environmental exposure are illustrated in Table 10. Neither the strengths nor the moduli change significantly when the joints are exposed to room temperature fluids. In some cases the strength improves slightly (10-15\%) during environmental conditioning. The beneficial effects of fluid and temperature are likely due to plasticization. The strength of joints immersed in hot (93C) water and in salt water for 30 days decrease by a factor of two. Loading (up to 30 percent of the baseline strength) during exposure does not seem to affect the strength.

The joints may fail by delamination of the composite or by separation of

Table 9. Baseline ("as received") lap shear strengths of adhesive bonded single lap joints.

\begin{tabular}{lcc}
\hline & \multicolumn{3}{c}{ Strength (MPa) } \\
\cline { 2 - 3 } & $23 C$ & $93 C$ \\
\hline XMC to SMC-R50 & 6.55 & 3.89 \\
SMC-R50 to SMC-R50 & 6.11 & 2.12 \\
SMC-R25 to SMC-R25 & 3.83 & - \\
\hline
\end{tabular}


Table 10. Changes in lap shear strength $\left(S / S_{B}\right)$ and modulus $\left(E / E_{B}\right)$ of adhesive bonded single lap joints after 30 days of environmental exposure at 23C (B-baseline value) (ref. 9).

\begin{tabular}{lccccc}
\hline & \multicolumn{2}{c}{ SMC-R25 to SMC-R25 } & & \multicolumn{2}{c}{ SMC-R50 to SMC-R50 } \\
\cline { 2 - 3 } \cline { 5 - 6 } Fluid & S/S & E/E $_{\mathbf{B}}$ & & S/S & E/E $_{\mathbf{B}}$ \\
\hline Air & 1.00 & 1.00 & 1.00 & 1.00 \\
Motor Oil & 0.89 & 1.05 & 0.85 & 0.92 \\
Transmission Fluid & 0.92 & 1.01 & 0.91 & 0.91 \\
Gasoline & 0.95 & 0.80 & 1.20 & 0.77 \\
Salt Water & 0.97 & 0.72 & 0.98 & 0.78 \\
Brake Fluid & 0.95 & 0.87 & 0.96 & 0.85 \\
Antifreeze & 0.96 & 1.15 & 0.81 & 0.81 \\
\hline
\end{tabular}

the adherent. In these tests, most failures occurred by delamination of the adherent. Separation of the adhesive was predominant only at higher (93C) temperatures.

Fatigue. Wang et al [9] conducted fatigue life tests on SMC-R25 to SMCR25 and SMC-R50 to SMC-R50 single lap joints. During the tests the stress levels were 30,50,70 and 90 percent of the static shear strength. Prior to the fatigue tests the specimens were soaked for 30 days at room temperature in the following liquids: $50 \%$ by weight salt water, motor oil, transmission fluid, and gasoline. The ranges of data are shown in Figure 14. The data are not shown separately for specimens immersed in the different fluids because the fluids did not have a significant effect on the fatigue life.

The residual strengths and moduli were also measured for specimens surviving for one million cycles [9]. Cyclic stressing at 30 percent of ultimate strength does not degrade appreciably either the strength or the modulus; in general, both the strength and the modulus retained at least 80 percent of their initial value.

Creep. Creep deformations of adhesive bonded single lap joints under

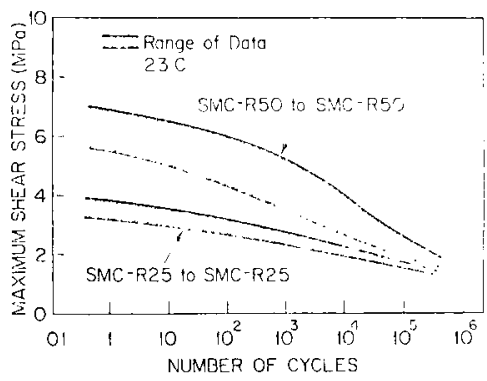

Figure 14. Maximum shear stress of adhesive bonded single lap joints (SMC-R50 to SMC-R50 and SMC-R25 to SMC-R25) during tension-tension fatigue (ref. 11). 

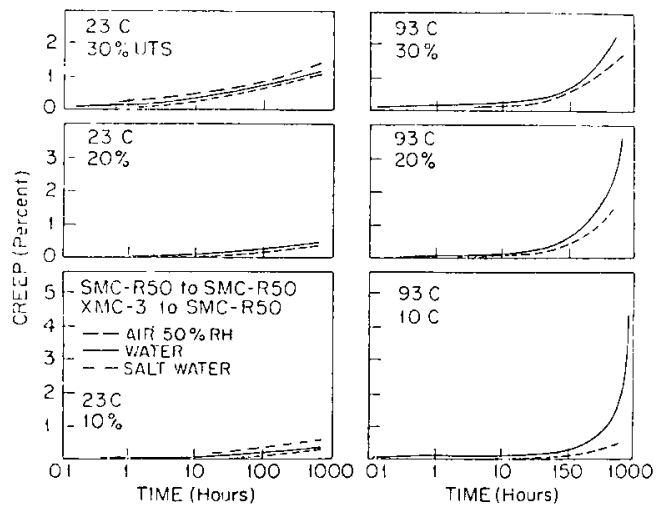

Figure 15. Creep of adhesive bonded single lap joints (SMC-R50 to SMC-RSO and XMC-3 to SMC-R50) immersed in air, water, and $5 \% \mathrm{NaCl}$-water mixture under different loads (percent of static ultimate tensile strength).

static and cyclic loadings are shown in Figures 15 and 16. These figures illustrate the effects of material, fluid, temperature, and applied load on creep behavior. The type of material used in forming the joints has smaller effect on creep than does the type of fluid, the temperature, and the applied load. The creep is lowest in air, and is higher in water, in salt water, and in hydrocarbons. The creep also increases with temperature and with applied load. For example, at 23C none of the XMC-3 to SMC-R50 or SMC-R50 to SMC-R50 joints failed during static creep. In air at $93 \mathrm{C}$ only one of the

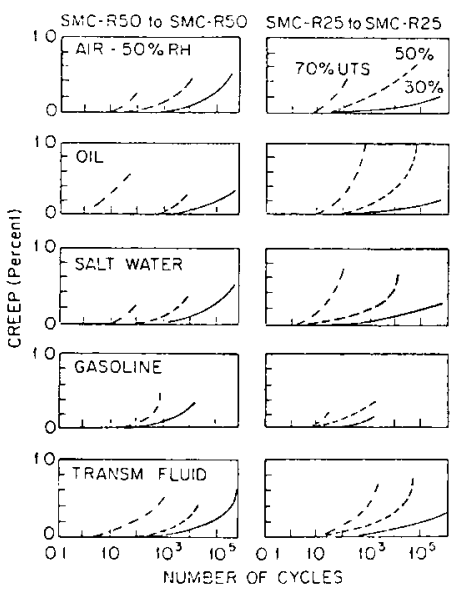

Figure 16. Creep of adhesive bonded single lap joints (SMC-RSO to SMC-RSO and SMC-R25 to SMC-R25) during tension-tension fatigue under different loads (-30\% UTS, $-50 \%$ UTS, $-70 \%$ UTS) (ref. 9). 
joints failed, this occurring at 30 percent load level. During water immersion (at 93C) all but 3 coupons failed before the end of the 715 hours test. During cyclic creep, only joints with 30 percent load survived for one million cycles. At higher loads none of the joints survived for one million cycles.

\section{VIBRATION DAMPING}

The vibration damping properties may be characterized by two parameters (the loss factor and the storage modulus) obtained by exciting the material with forced sinusoidal oscillations and by measuring the input stress and output strain [3]. The loss factor is the tangent of the phase angle between the stress and the strain, and is equal to the ratio between the energy dissipated and the energy stored in the material. The storage modulus is the in-phase component of the ratio of input stress to output strain.

The effects of temperature and soaking in different types of liquids are illustrated in Tables 11 and 12. An increase in temperature (from $23 \mathrm{C}$ to $120 \mathrm{C}$ ) increases the damping and reduces the stiffness. Soaking in liquids has similar effects. Soaking for 1000 hours considerably increased the damping of chopped fiber composites (SMC-R25 and SMC-R60), while their stiffness decreased slightly. The damping characteristics of continuous fiber composites (XMC-3 and SMC-C20/R30) change little in the fiber direction. It is noteworthy that both temperature and moisture-induced changes in the vibration properties appear to be reversible [11].

\section{MOISTURE ABSORPTION}

Glass fiber reinforced organic matrix composites absorb moisture when exposed to humid air or to liquids. The weight changes of different types of SMC composites exposed to different types of fluids are presented in Figures $17-19$. The weight change (M) is defined as

Table 11. Loss factor and storage modulus at 23C, and maximum changes in these parameters when the temperature is increased from $23 \mathrm{C}$ to $120 \mathrm{C}$ (L-longitudinal, T-transverse direction) (refs. 3, 10).

\begin{tabular}{lccccc}
\hline & \multicolumn{2}{c}{$\begin{array}{c}\text { Loss Factor } \\
\text { at 23C }\end{array}$} & Storage Modulus at 23C & $\begin{array}{c}\text { Max. } \\
\text { Change }\end{array}$ & Percent \\
\cline { 2 - 5 } Material & $\mathbf{0 . 1 ~ H z ~} \mathbf{1 0 ~ H z}$ & (GPa) & Loss Factor Storage Modulus \\
\hline XMC-3(L) & 0.028 & 0.025 & 36 & +129 & -7 \\
XMC-3(T) & 0.063 & 0.053 & - & +355 & -54 \\
SMC-C20/R30(L) & 0.034 & 0.029 & - & +80 & -5 \\
SMC-C20/R30(T) & 0.051 & 0.049 & - & +204 & -44 \\
SMC-R25 & 0.037 & 0.035 & 4 & +471 & -48 \\
SMC-R65 & 0.0390 .034 & 8 & +241 & -30 \\
Steel & $\sim 0.001$ & & & \\
\hline
\end{tabular}




$$
\mathrm{M}=\frac{\text { wet weight-dry weight }}{\text { dry weight }} \times 100 \text { percent }
$$

The data show that, in general, when the dry material is submerged in the fluid the weight at first increases then levels off for some length of time. Both the initial rate of weight increase and the value at which the weights level off depend on a) the material, b) the temperature, and c) the environment (relative humidity of air or the type of liquid used). The data also show that in some instances the weight does not remain constant after it reaches a level value but keeps either increasing or decreasing. This suggests that under some conditions the moisture transport is by a non-Fickian process. One reason for the non-Fickian behavior may be that moisture transfer through the resin does not proceed by a process that can be described by Fick's law. Another plausible explanation of the observed non-Fickian absorption process is as

Table 12. Maximum changes in dynamic properties during 1000 hours of soak (L-Jongitudinal, T-transverse direction) (ref. 11).

\begin{tabular}{|c|c|c|c|}
\hline \multirow[b]{2}{*}{ Fluid } & \multirow[b]{2}{*}{ Material } & \multicolumn{2}{|c|}{ Maximum Change (percent) } \\
\hline & & Loss Factor & Storage Modulus \\
\hline $\begin{array}{l}\text { Distilled } \\
\text { Water 22C }\end{array}$ & $\begin{array}{l}\text { XMC-3(L) } \\
\text { SMC-C20/R30(L) } \\
\text { SMC-R25 } \\
\text { SMC-R65 }\end{array}$ & $\begin{array}{l}+53 \\
+\quad 38 \\
+193 \\
+180\end{array}$ & $\begin{array}{r}0 \\
0 \\
-20 \\
-\quad 7\end{array}$ \\
\hline $\begin{array}{l}\text { Distilled } \\
\text { Water } 50 \mathrm{C}\end{array}$ & $\begin{array}{l}\text { XMC-3(L) } \\
\text { SMC-C20/R30(L) } \\
\text { SMC-R25 } \\
\text { SMC-R65 }\end{array}$ & $\begin{array}{l}+88 \\
+112 \\
+210 \\
+247\end{array}$ & $\begin{array}{r}0 \\
0 \\
-10 \\
-12\end{array}$ \\
\hline $\begin{array}{l}\text { Salt } \\
\text { Water 23C }\end{array}$ & $\begin{array}{l}X M C-3(L) \\
\text { SMC-C20/R30(L) } \\
\text { SMC-R25 } \\
\text { SMC-R65 }\end{array}$ & $\begin{array}{l}+55 \\
+50 \\
+117 \\
+178\end{array}$ & $\begin{array}{r}0 \\
0 \\
-\quad 4 \\
-\quad 7\end{array}$ \\
\hline $\begin{array}{l}\text { Motor } \\
\text { Oil 23C }\end{array}$ & $\begin{array}{l}X M C-3(L) \\
\text { SMC-C20/R30(L) } \\
\text { SMC-R25 } \\
\text { SMC-R65 }\end{array}$ & $\begin{array}{r}0 \\
0 \\
+\quad 25 \\
+\quad 24\end{array}$ & $\begin{array}{l}0 \\
0 \\
0 \\
0\end{array}$ \\
\hline Antifreeze & $\begin{array}{l}\text { XMC-3(L) } \\
\text { SMC-C20/R30(L) } \\
\text { SMC-R25 } \\
\text { SMC-R65 }\end{array}$ & $\begin{array}{r}0 \\
0 \\
+\quad 29 \\
+\quad 22\end{array}$ & $\begin{array}{l}0 \\
0 \\
0 \\
0\end{array}$ \\
\hline Gasoline 22C & $\begin{array}{l}\text { XMC-3(L) } \\
\text { SMC-C20/R30(L) } \\
\text { SMC-R25 } \\
\text { SMC-R65 }\end{array}$ & $\begin{array}{r}0 \\
0 \\
178 \\
30\end{array}$ & $\begin{array}{r}0 \\
0 \\
-15 \\
0\end{array}$ \\
\hline
\end{tabular}



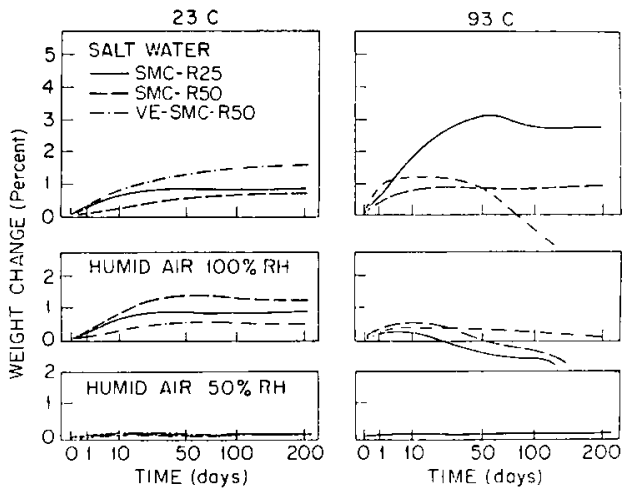

Figure 17. Weight change during immersion in humid air and in saturated salt water (ref. 4).

follows. Owing to the moist, high temperature environment, microcracks develop on the surface and inside the material. Moisture rapidly enters the material, causing an increase in weight. As the cracks grow larger, material, most likely in the form of resin particles, is actually lost. In fact, such material loss is frequently observed after a few hours of exposure to the moist environment. As long as the moisture gain is greater than the material loss, the weight of the specimen increases. Once the weight of the lost material exceeds the weight of the absorbed moisture, the weight of the specimen
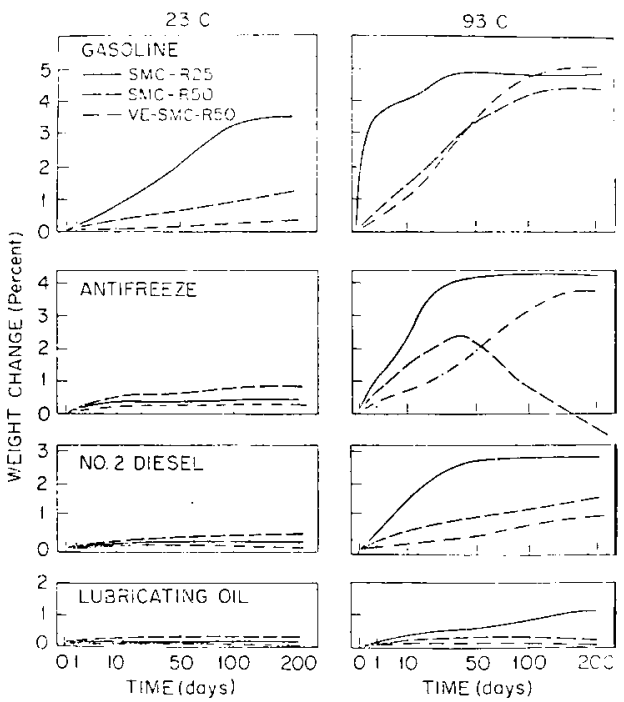

Figure 18. Weight change during immersion in different types of hydrocarbons (refs. 4, 12). 


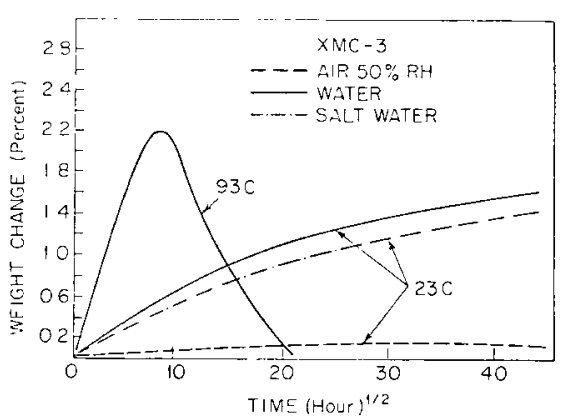

Figure 19. Weight change of XMC-3 immersed in humid air, water, and in $5 \% \mathrm{NaCl}$-water mixture (ref. 4).

decreases. Of course, when the material is lost, the measured weight change no longer corresponds to the moisture content of the material.

The foregoing results were all obtained with unstressed specimens. However, the moisture absorption characteristics of stressed and unstressed SMC materials do not differ appreciably.

\section{THERMAL EXPANSION}

The dimensional changes of the material during temperature cycles must be taken into account in the design process. The thermal expansion coefficient values reported by Heimbuch and Sanders [2] and by Riegner and Sanders [3] are reproduced in Table 13. As expected, the thermal expansion coefficients are lowest along the fiber direction of composites containing continuous fibers (XMC-3 and SMC-C20/R30). The coefficient is high in the transverse direction of these materials and also for SMC-R25 composites. More com-

Table 13. Thermal expansion coefficient a at room temperature (L-longitudinal, T-transverse direction) (refs. 2,3).

\begin{tabular}{lc}
\hline Material & $\alpha\left(\mu \mathrm{m} / \mathrm{m}^{\circ} \mathrm{C}\right)$ \\
\hline XMC-3(L) & 8.7 \\
XMC-3(T) & 28.6 \\
SMC-C20/R30(L) & 11.3 \\
SMC-C20/R30(T) & 24.6 \\
SMC-R25 & 23.2 \\
SMC-R50 & 14.8 \\
SMC-R65 & 13.7 \\
\hline
\end{tabular}


prehensive data on the variation of the thermal expansion coefficient with temperature are not yet available.

\section{ACKNOWLEDGMENTS}

This work was supported by the Materials Laboratory, U.S. Air Force Systems Command, Wright Patterson Air Force Base, Dayton, Ohio.

\section{REFERENCES}

1. Springer, G. S., "Properties of Organic Matrix Short Fiber Composites", Materials Laboratory, Air Force Systems Command, Report AFWAL-TR-82-4004, Wright Patterson Air Force Base, Dayton, Ohio (1982).

2. Heimbuch, R. A. and Sanders, B. A., "Mechanical Properties of Chopped Fiber Reinforced Plastics", in Composite Materials in the Automotive Industry, American Society of Mechanical Engineers, pp. 111-139. (1978).

3. Riegner, D. A. and Sanders, B. A., "A Characterization Study of Automotive Continuous and Random Glass Fiber Composites", Report GMMD 79-023, General Motors Corporation, Manufacturing Development, GM Technical Center, Warren, Michigan, 48090 (1979).

4. Springer, G. S., Sanders, J. A., and Tung, R. W. "Environmental Effects on Glass Fiber Reinforced Polyester and Vinylester Composites", J. Composite Materials, 14, pp. 213-232. (1980).

5. Denton, D. L., "Mechanical Properties Characterization of an SMC-R50 Composite", 34th Annual Technical Conference, Reinforced Plastics/Composites Institute, The Society of the Plastics Industry, 1979, Section 11-F; also SAE Paper 790671 (1979).

6. Enos, J. H., Erratt, R. L., Grancis, E. and Thomas, R. E., "Structural Performance of Vinylester Resin Compression Molded High Strength Composites", 34th Annual Technical Conference, Reinforced Plastics/Composites Institute, The Society of Plastics Industry, 1979, Section 11-E.

7. Adams, D. F. and Walrath, D. E., "Iosipescu Shear Properties of SMC Composite Materials", Department of Mechanical Engineering, The University of Wyoming, Larrabee, Wyoming, 82738 (1981)

8. Ackley, R. H. and Carley, E. P., "XMC-3 Composite Material Structural Molding Compound", 34th Annual Technical Conference, Reinforced Plastics/Composites Institute, The Society of Plastics Industry, 1979, Section 21-D.

9. Wang, T. K., Sanders, B. A. and Lindholm, U.S., “A Loading Rate and Environmental Effects Study of Adhesive Bonded SMC Joints", Report GMMD80-044, General Motors Corporation, Manufacturing Development, GM Technical Center, Warren, Michigan, 48090 (1980).

10. Seiffert, V. W., "Review of Recent Activities and Trends in the Field of Automobile Materials", in Worldwide Applications of Plastics, Society of Automotive Engineers, SP-482 pp. 1-6 (1981).

11. Gibson, R. F., Yau, A. and Riegner, D. A. "The Influence of Environmental Conditions on the Vibration Characteristics of Chopped-Fiber-Reinforced Composite Materials", Presented at AIAA/ASME/ASCE/AHS 22nd Structure, Structured Dynamics and Materials Conference (1981).

12. Loos, A. C., Springer, G. S., Sanders, B. A. and Tung, R. W., "Moisture Absorption of Polyester-E Glass Composites", J. Composite Materials, 14, pp. 142-154 (1980). 